\title{
The association of dyslipidemia and obesity with glycated hemoglobin
}

\author{
Jayesh Sheth ${ }^{1 *}$, Ankna Shah ${ }^{1}$, Frenny Sheth ${ }^{1}$, Sunil Trivedi ${ }^{1}$, Nutan Nabar ${ }^{2}$, Navneet Shah ${ }^{3}$, Premal Thakor ${ }^{4}$ \\ and Rama Vaidya ${ }^{2}$
}

\begin{abstract}
Background: Dyslipidemia and obesity are the most common complex metabolic disorders taking the highest toll of health resources globally by its increasing incidences. This consequently leads to type 2 diabetes mellitus (T2DM) and cardiovascular disorders (CVDs) with variable reports about the role of metabolic factors on glycemic control. The current study is designed to determine the association of dyslipidemia and obesity with glycated hemoglobin (HbA1c) in T2DM and non-diabetic subjects.
\end{abstract}

Methods: The present study was carried out in 931 subjects from urban Western India including 430 diabetic and 501 non-diabetic subjects with detailed anthropometric parameters. All subjects were investigated for HbA1c and lipid parameters like TC, TG, HDL-C, LDL-C and non-HDL-C.

Results: Dyslipidemia, central- and peripheral- obesity were observed (50.27 \%; $75 \%$ and $59.83 \%$ ) in all the study subjects respectively. Additionally, hyper-non-HDL-C was detected in $23.49 \%$ and $22.56 \%$ in T2DM and non-diabetic subjects. Significant linear associations of hyper-TC, hyper-LDL-C and hyper-non-HDL-C were observed with HbA1c in T2DM and non-diabetic control subjects respectively. Centrally- and peripherally-obese dyslipidemic subjects also showed a significant association with HbA1c in T2DM and control subjects respectively.

Conclusion: This study demonstrates the high prevalence of dyslipidemia and obesity in all subjects irrespective of their disease status in a Western Indian population. The dyslipidemic obese subjects had significant linear association with HbA1c in T2DM subjects.

Keywords: Dyslipidemia, Obesity, T2DM, HbA1c, non-HDL-C

\section{Background}

Dyslipidemia is associated with more than half of cases with ischemic heart disease and more than 4 million deaths per year [1]. In India, a rise in obesity and dyslipidemia with increasing urbanization have led to various lifestyle related disorders like T2DM, CVD and metabolic syndrome [1]. Among dyslipidemic subjects, increased LDL-C, TG and hypo-HDL are established markers for CAD risk. Additionally, TG-rich lipoproteins like VLDL and IDL contribute to total atherogenic cholesterol and are reflected by non-HDL-C which can be used as a secondary target for lipid lowering agents as proposed by the National Cholesterol Education Program, Adult

\footnotetext{
* Correspondence: jshethad1@gmail.com

'Department of Biochemistry and Molecular Genetics, FRIGE's Institute of Human Genetics, FRIGE House, Jodhpur Gam Road, Satellite, Ahmedabad 380015, India

Full list of author information is available at the end of the article
}

Treatment Panel III (NCEP-ATP III) [2, 3] and may be used as the best risk predictor for stroke and cardiovascular complications [3].

Moreover, more than half a billion people worldwide are obese $[4,5]$ and has serious impact on multiple health outcomes [6]. World Health Organization (WHO) recognizes obesity and its complications amongst the top 10 global risk factors leading to $\sim 40 \%$ global deaths [7]. The menace of obesity is attaining an epidemic worldwide due to changes in life style and food habits. It is defined as a state of excess adipose tissue mass, and not by the body weight alone since muscular individuals may possibly have overall weight gain or high body mass index (BMI) without an increase in adiposity. Thus, those who are not peripherally obese or overweight might be centrally obese with high percentage of body fat distributed predominantly in the abdominal region [8]. In centrally obese individuals, 
adipose tissue releases higher amounts of non-esterified fatty acids (NEFA), glycerol, hormones, pro-inflammatory cytokines contributing to insulin resistance (IR) $[9,10]$. Asian Indians are found to have higher intra-abdominal fat, visceral fat and metabolic disturbances as compared to Caucasians $[8,11]$ with 3 out of 4 (73\%) urban Indians being overweight [12]. Based on recently reported prevalence of obesity in India, it has been shown that every second urban Indian is obese with the highest risk of weight gain between $28-38$ years [12].

These metabolic dysregulators like dyslipidemia and obesity along with other lifestyle factors are known to be associated with T2DM, [2, 13-15] characterized by hyperglycemia [16]. As per the International Diabetes Federation (IDF) 2013 estimate, India ranks second amongst the top 10 countries with 65.1 million diabetic subjects with an alarming high rate. It is further set to increase up to 109.0 million with a global estimate of 592 million by the year 2035 [17].

IDF estimates that nearly 175 million individuals are undiagnosed with diabetes globally [17]. The disease manifestation takes place much before its clinical appearance; subjects with T2DM are often asymptomatic initially as early as 12 years before the diagnosis and continue to remain asymptomatic throughout the disease process. Consequently, the age of diagnosis may not accurately reflect the age of onset of the disease [18].

It will be fruitful to detect early diabetics in India to curtail the ever increasing incidence of T2DM so that suitable lifestyle modifications may be suggested to prevent or postpone the onset of T2DM. Our study therefore attempted to demonstrate the influence of dyslipidemia and obesity on $\mathrm{HbA1c}$ in diabetic and non-diabetic subjects and whether can it be advocated as a combined 'biomarker of lifestyle pattern'. Moreover, the novelty of the study is an attempt to demonstrate the association of combined effect of dyslipidemia and obesity on HbA1c in Western Indian urban population due to paucity of such studies [19].

\section{Methods}

\section{Subjects}

The current prospective study was carried out on the Western Indian population (Gujarat and Maharashtra) that comprised of 931 unrelated participants (430 previously diagnosed T2DM patients and 501 non-diabetic control subjects) in the age range of 25 to 89 years. They were enrolled by consecutive sampling during April, 2012 to October, 2014. All T2DM subjects satisfied the inclusion criteria of age $\geq 25$ years, duration of diabetes ( $\geq 6$ months from the date of diagnosis) and plasma glucose level [Fasting plasma glucose (FPG) $>126.0 \mathrm{mg} / \mathrm{dl}$, post prandial plasma glucose (PPPG) $>190.0 \mathrm{mg} / \mathrm{dl}]$. The inclusion criteria for control subjects were age $\geq 25$ years, plasma glucose level (FPG) $<110.0 \mathrm{mg} / \mathrm{dl}$ ) and $\mathrm{HbA} 1 \mathrm{c}$ level $\leq 6.5 \%$. The study was approved by the institutional ethical committee and ISBEC (Intersystem Biomedica Ethics Committee). Informed written consent from all participating subjects was obtained prior to the enrolment. Those with T1DM, other concomitant illness, lactating and pregnant mothers and those who were on medication of lipid lowering agents (statins, fibrates) were excluded from the study. Anthropometric parameters such as BMI, waist circumference (WC) and duration of T2DM were recorded for all the participating subjects as shown in Table 1. T2DM patients were treated with biguanides, sulphonylureas, PPARY activators, DPP4 inhibitors and $\alpha$ glucosidase inhibitors alone or in combinations as advised by their physicians.

\section{Anthropometric indices}

Weight was measured with light clothes and without shoes using a digital scale (to the nearest $0.1 \mathrm{~kg}$ ). Height was measured without shoes using a stadiometer (to the nearest $0.1 \mathrm{~cm}$ ). Waist circumference was measured to the nearest $0.1 \mathrm{~cm}$. BMI was calculated using the equation "BMI $=$ weight $/$ height $^{2}\left(\mathrm{~kg} / \mathrm{meter}^{2}\right)$ ". The cut offs

Table 1 Anthropometric and biochemical parameters in T2DM and control subjects

\begin{tabular}{|c|c|c|c|}
\hline \multirow{2}{*}{$\begin{array}{l}\text { Parameters } \\
(\mathrm{T}=931 \text { subjects })\end{array}$} & \multirow{2}{*}{$\begin{array}{l}\text { T2DM }(n=430) \\
\text { Mean } \pm \text { SD (range) }\end{array}$} & \multirow{2}{*}{$\begin{array}{l}\text { Control }(\mathrm{n}=501) \\
\text { Mean } \pm \text { SD (range) }\end{array}$} & \multirow[t]{2}{*}{$p$ value } \\
\hline & & & \\
\hline \multicolumn{4}{|c|}{ Anthropometric indices } \\
\hline \multirow[t]{2}{*}{ Age (Yrs.) } & $56.57 \pm 10.52$ & $48.60 \pm 12.95$ & - \\
\hline & $(28.0-86.0)$ & $(25.0-86.0)$ & \\
\hline \multirow[t]{2}{*}{ BMI $\left(\mathrm{Kg} / \mathrm{m}^{2}\right)$} & $27.34 \pm 5.12$ & $25.83 \pm 4.62$ & 0.092 \\
\hline & $(16.26-51.31)$ & $(12.70-47.42)$ & \\
\hline \multirow[t]{2}{*}{ WC (cm) } & $96.88 \pm 10.28$ & $92.11 \pm 10.72$ & 0.542 \\
\hline & $(65.0-142.0)$ & $(64.0-128.0)$ & \\
\hline \multicolumn{4}{|c|}{ Biochemical Parameters } \\
\hline FPG (mg/dl) & $140.79 \pm 48.31$ & $88.27 \pm 12.39$ & $<0.001^{*}$ \\
\hline PPPG (mg/dl) & $189.53 \pm 66.85$ & ND & - \\
\hline HbA1c (\%) & $8.18 \pm 1.81$ & $5.68 \pm 0.51$ & $<0.001^{*}$ \\
\hline FI (ulU/ml) & $11.02 \pm 6.47$ & $11.97 \pm 5.44$ & 0.487 \\
\hline HOMA-IR & $3.85 \pm 2.30$ & $2.67 \pm 1.56$ & $<0.001^{*}$ \\
\hline $\mathrm{TC}(\mathrm{mg} / \mathrm{dl})$ & $181.56 \pm 52.01$ & $181.97 \pm 46.18$ & $0.008^{*}$ \\
\hline TG (mg/dl) & $142.04 \pm 73.30$ & $112.03 \pm 53.80$ & $<0.001^{*}$ \\
\hline HDL-C (mg/dl) & $54.24 \pm 16.77$ & $56.79 \pm 17.33$ & 0.151 \\
\hline LDL-C (mg/dl) & $97.94 \pm 50.33$ & $102.13 \pm 45.14$ & 0.079 \\
\hline Non-HDL-C (mg/dl) & $127.32 \pm 53.21$ & $125.18 \pm 47.10$ & $0.034^{*}$ \\
\hline
\end{tabular}

By Independent Student's $t$-test, *: Significant, SD: Standard deviation BMI: Body mass index, WC: Waist circumference, FPG: Fasting plasma glucose, PPPG: Post prandial plasma glucose, HbA1c: Glycated hemoglobin, Fl: Fasting Insulin, HOMA-IR: Homeostasis Model of Assessment-Insulin Resistance Index, TC: Total cholesterol, TG: Triglycerides, HDL-C: High-density lipoprotein cholesterol, LDL-C: Low-density lipoprotein cholesterol, Non-HDL-C: TC-HDL-C 
used in this study to characterize participants for obesity were based on the Executive Summary of the Third Report of the NCEP, ATP III and the IDF guidelines for SouthAsian population $[2,17]$. Obesity as a whole was defined as BMI $>25 \mathrm{~kg} / \mathrm{m}^{2}$; and central obesity was defined as WC $>90 \mathrm{~cm}$ for males and $\mathrm{WC}>80 \mathrm{~cm}$ for females.

\section{Sample collection and handling}

Blood samples were collected in fluoride, EDTA and serum vaccutainers between 8:00 to 11:00 am after $12 \mathrm{~h}$ of fasting for biochemical assays such as FPG, HbA1c, fasting insulin (FI), insulin resistance (HOMA-IR), and lipid profile estimation. Blood was collected again after $2 \mathrm{~h}$ of consuming non-standardized meal for PPPG estimation for T2DM subjects. Serum was separated within 30-45 min, aliquoted and stored at $-20{ }^{\circ} \mathrm{C}$ till analysis.

\section{Biochemical investigations}

FPG, PPPG and lipid profile including total cholesterol (TC), triglyceride (TG), and high-density lipoprotein cholesterol (HDL-C) were measured by colorimetric method with respective calibrator and biological standards. All biochemical investigations were carried out by commercially available kits using an auto-analyzer system (BTS 330, Biosystem, Spain). HbA1c was analyzed by affinity assay using the Nyco Card reader-II (AxisShield, Norway). FI levels were measured by Immuno Radiometric Assay (IRMA) with a commercial kit (Immunotech, France). Low-density lipoprotein cholesterol (LDL-C) and non-HDL-C were calculated by a standard formula $[\mathrm{LDL}=\mathrm{TC}-\mathrm{HDL}-\mathrm{C}-(\mathrm{TG} / 5)]$ and [non-HDL-C $=$ TC - HDL-C] [20]. Insulin resistance was calculated by the Homeostasis Model of AssessmentInsulin Resistance Index (HOMA-IR) with a model formula $[$ HOMA-IR $=(\mathrm{FI} \times \mathrm{FPG}) / 405]$ [21].

The intra assay coefficients of variations for lipid parameters were; TC: $1.39 \%$, TG: $0.50 \%$ and HDL-C: $1.67 \%$ whereas the inter assay coefficients of variations for aforesaid lipids were; $2.65 \%, 1.65 \%$ and $4.69 \%$ respectively.

The cut offs for dyslipidemia used in this study were based on the IDF guidelines for South-Asian population. The hypercholesterolemia (hyper-TC) and hypertriglyceridemia (hyper-TG) were considered with TC $\geq 220 \mathrm{mg} / \mathrm{dl}$ and $\mathrm{TG} \geq 150 \mathrm{mg} / \mathrm{dl}$ respectively; whereas, those with HDL-C $\leq 40 \mathrm{mg} / \mathrm{dl}$, LDL-C $\geq 130 \mathrm{mg} / \mathrm{dl}$ and non-HDL-C $\geq$ $160 \mathrm{mg} / \mathrm{dl}$ were considered hypo-HDL-cholesterolemia (hypo-HDL-C), hyper-LDL-cholesterolemia (hyper-LDL-C) and hyper-non-HDL-cholesterolemia (hyper-non-HDL-C) respectively. $\mathrm{TC}<220 \mathrm{mg} / \mathrm{dl}, \mathrm{TG}<150 \mathrm{mg} / \mathrm{dl}, \mathrm{HDL}-\mathrm{C}>$ $40 \mathrm{mg} / \mathrm{dl} \mathrm{LDL-C}<130 \mathrm{mg} / \mathrm{dl}$ and non-HDL-C $<160 \mathrm{mg} / \mathrm{dl}$ were regarded as normal in accordance with IDF and NCEP guidelines $[2,17]$. Dyslipidemia is defined by presence of one or more abnormal serum lipid biomarker concentration.

\section{Statistical analysis}

The sample size yielded a margin of error of $3.3 \%$ in the study and a confidence limit of $95 \%$ with an on-line calculator [22]. False positive error rate/Type I error was 0.05 . The value of HbA1c was given as a percentage of total hemoglobin; and values of all other lipid parameters were given in $\mathrm{mg} / \mathrm{dl}$. All values were expressed as mean \pm standard deviation. Linear regression, bivariate correlation analysis (using Pearson's correlation coefficient) and student's $t$-test analysis were carried out with IBM-SPSS v15.0. $p$ values (two tailed) $\leq 0.05$ were considered to be statistically significant.

\section{Results}

\section{Assessment of Anthropometric indices and Biochemical parameters}

Total 931 subjects were included in the study, 430 were T2DM (diagnosed for $>6$ months) and 501 were nondiabetic control subjects. Baseline characteristics of the participants are summarized in Table 1. The average duration of diabetes in T2DM subjects at inclusion was $8.39 \pm 7.53$ years (6 months to 40 years). Significantly

Table 2 Correlation of HbA1c on dyslipidemia and obesity

\begin{tabular}{|c|c|c|c|c|c|c|}
\hline \multirow{3}{*}{$\begin{array}{l}\text { Parameters } \\
(\mathrm{T}=931 \text { subjects) }\end{array}$} & \multirow{2}{*}{\multicolumn{3}{|c|}{$\begin{array}{l}\text { T2DM }(\mathrm{N}=430) \\
\text { Association with } \mathrm{HbA} 1 \mathrm{c}\end{array}$}} & \multirow{2}{*}{\multicolumn{3}{|c|}{$\begin{array}{l}\text { Controls }(\mathrm{N}=501) \\
\text { Association with } \mathrm{HbA} 1 \mathrm{c}\end{array}$}} \\
\hline & & & & & & \\
\hline & $r^{2}$ & $r$ & $p$ & $r^{2}$ & $r$ & $p$ \\
\hline \multicolumn{7}{|l|}{ Lipid parameters } \\
\hline Hyper TC & 0.098 & 0.312 & $0.004^{*}$ & 0.030 & 0.172 & $0.003^{*}$ \\
\hline Normal TC & 0.06 & 0.096 & 0.085 & 0.006 & 0.077 & 0.125 \\
\hline Hyper TG & 0.001 & 0.036 & 0.670 & 0.000 & 0.010 & 0.921 \\
\hline Normal TG & 0.002 & 0.043 & 0.483 & 0.000 & 0.019 & 0.705 \\
\hline Hyро HDL & 0.000 & -0.009 & 0.935 & 0.030 & -0.174 & 0.106 \\
\hline Normal HDL & 0.002 & -0.050 & 0.369 & 0.012 & -0.109 & $0.027^{*}$ \\
\hline Hyper LDL & 0.101 & 0.317 & $0.001^{*}$ & 0.036 & 0.189 & $0.031^{*}$ \\
\hline Normal LDL & 0.004 & 0.061 & 0.280 & 0.023 & 0.152 & $0.004^{*}$ \\
\hline Hyper non-HDL-C & 0.137 & 0.370 & $<0.001^{*}$ & 0.050 & 0.224 & $0.017^{*}$ \\
\hline Normal non-HDL-C & 0.001 & 0.030 & 0.598 & 0.031 & 0.176 & $0.001^{*}$ \\
\hline \multicolumn{7}{|l|}{ Obesity } \\
\hline Higher WC & 0.000 & 0.010 & 0.854 & 0.001 & 0.028 & 0.599 \\
\hline Normal WC & 0.002 & 0.044 & 0.715 & 0.012 & 0.110 & 0.194 \\
\hline Higher BMI & 0.000 & 0.009 & 0.887 & 0.012 & 0.110 & 0.071 \\
\hline Normal BMI & 0.003 & 0.099 & 0.243 & 0.012 & 0.112 & 0.095 \\
\hline
\end{tabular}

By Linear regression and bivariate analysis using Pearson's correlation coefficient considering $\mathrm{HbA} 1 \mathrm{c}$ as a dependent variable, *: Significant BMI: Body mass index, WC: Waist circumference, TC: Total cholesterol, TG: Triglycerides, HDL-C: High-density lipoprotein cholesterol, LDL-C: Low-density lipoprotein cholesterol, non-HDL-C: TC-HDL

Hyper TC: TC $\geq 220 \mathrm{mg} / \mathrm{dl}$, Hyper TG: TG $\geq 150 \mathrm{mg} / \mathrm{dl}$ respectively, Hypo-HDL: HDL-C $\leq 40 \mathrm{mg} / \mathrm{dl}$, Hyper-LDL: LDL-C $\geq 130 \mathrm{mg} / \mathrm{dl}$, Hyper-Non-HDL: Non-HDL-C $\geq$ $160 \mathrm{mg} / \mathrm{dl}$, Higher WC: Male WC $>90 \mathrm{~cm}$ and Female WC $>80 \mathrm{~cm}$, Higher BMI: $\mathrm{BMI}>25 \mathrm{~kg} / \mathrm{m}^{2}$ 
higher mean FPG and HbA1c were observed in T2DM as compared to non-diabetic control subjects (FPG: $\mathrm{p}<$ 0.001 and HbA1c: $\mathrm{p}<0.001$ ) respectively. Additionally, higher mean HOMA-IR, TC, TG and non-HDL-C were also observed in T2DM than in non-diabetic control subjects (HOMA-IR: $\mathrm{p}<0.001$, TC: $\mathrm{p}=0.008$, TG: $\mathrm{p}<$ 0.001 and non-HDL-C: $\mathrm{p}=0.034$ ) respectively.

\section{Prevalence of dyslipidemia and obesity}

Dyslipidemia was seen in $50.27 \%$ of the study population with highest in T2DM amongst both the groups followed by control subjects ( $53.72 \%$ and $47.31 \%$ respectively). HyperTC was observed in $19.76 \%$ (85) and $20.56 \%$ (103) of T2DM and control subjects respectively. Hyper-TG was higher in T2DM compared to control subjects [33.26\% (143) $19.56 \%$ (98)], whereas hypo-HDL-C was $18.61 \%$ (80) in T2DM and $17.54 \%$ (88) in non-diabetic subjects. Furthermore, prevalence of hyper-LDL-C and hyper-nonHDL-C were almost at par in both the groups $23.02 \%$ (99); vs. $25.95 \%$ and $23.49 \%$ (101) vs. $22.56 \%$ (113) in T2DM compared to control subjects respectively (Data not shown).

The prevalence of central obesity was found to be higher (75 \%) compared to peripheral obesity $(59.83 \%)$ in overall study population. Higher central obesity was seen in T2DM as compared to non-diabetic control subjects [82.56 \% (355) vs. $70.26 \%$ (352)] respectively. Similarly, incidence of peripheral obesity was also higher in T2DM than non-diabetic control subjects [66.27 \% (283) vs. $54.29 \%$ (272)] respectively (Data not shown).

\section{Association of dyslipidemia, central obesity and peripheral obesity with $\mathrm{HbA1c}$ levels}

A significant linear association of hyper-TC, hyper-LDL-C and hyper-non-HDL-C with HbA1c was observed in T2DM and control subjects. Though, significant correlation between hyper-TG and hypo-HDL-C to HbA1c was not observed in subjects of the both groups (Table 2). Additionally, we also observed an association between normal HDL-C, LDL-C and non-HDL-C with HbA1c in control subjects. Though, higher WC or higher BMI per se had no independent association with HbA1c levels in any of the groups as shown in Table 2.

Nonetheless, significant linear association was observed in T2DM subjects with central- and peripheralobesity along with dyslipidemia, while such correlation was not seen in non-diabetic subjects (Figs. 1 and 2).

\section{Discussion}

The present population-based study was carried out on subjects from urban Western India with a mixed ethnicity. The major contributing factor for the higher risk of developing diabetes is likely to be due to increased prevalence of central- and peripheral- obesity in all the study subjects which is almost similar to the previous observation of 30-65 \% Indian urban being overweight or obese [23]. Obesity is known to be associated with increased amount of adipose tissue or its disproportionate distribution between central- and peripheral- body regions which is also related to the development of insulin resistance, dyslipidemia and CAD that increases the

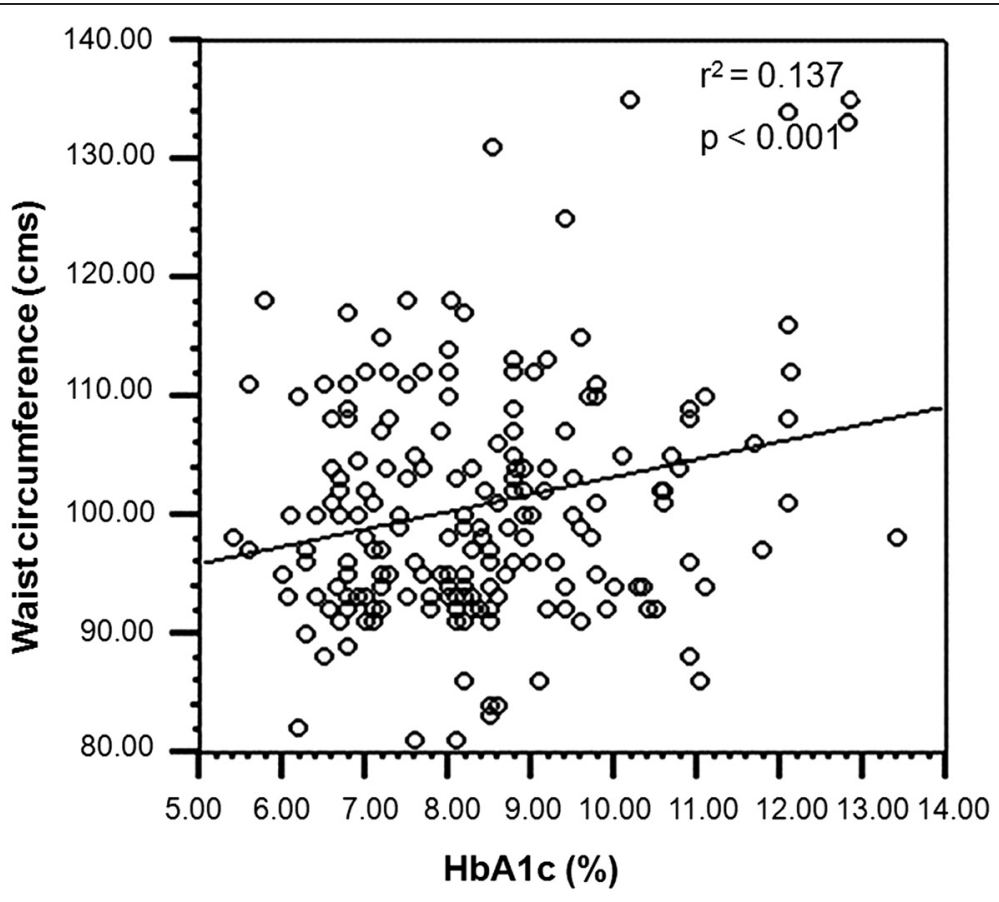

Fig. 1 Association of central obesity with $\mathrm{HbA} 1 \mathrm{C}$ in dyslipidemic T2DM subjects 


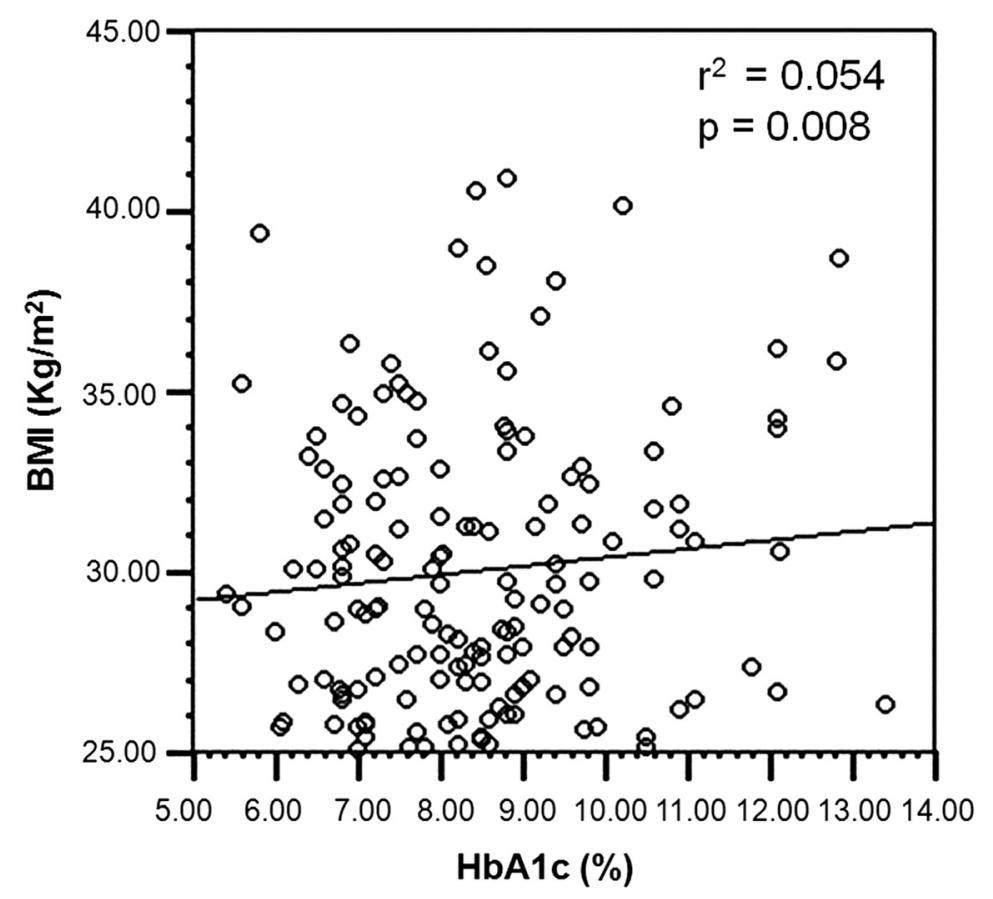

Fig. 2 Association of peripheral obesity with $\mathrm{HbA1c}$ in dyslipidemic T2DM subjects

susceptibility of developing T2DM [24]. In addition to the storage of lipids in the adipose tissue, adipocytokines like adiponectin, leptin, TNF, IL-6, resistin play an important role in tissue physiology and have been shown to be linked to obesity, insulin resistance and $\beta$-cell dysfunction [24]. McTernan et al. in their animal study showed an increased resistin expression in adipose cells obtained from abdominal and omental region possibly contributing to insulin resistance, glucose intolerance and development of T2DM [25]. This could explain why obese T2DM subjects with dyslipidemia had poor hemoglobin glycation as compared to non-obese T2DM subjects in our study. The present study showed a higher number of T2DM subjects with central obesity as compared to peripheral obesity, which could be due to higher rates of lipolysis in visceral fat than subcutaneous fat by catecholamines [26]. This may in turn result into an increased FFA delivery to the liver, consequently stimulates hepatic glucose production by fatty acids (FA) causing interference in hepatic insulin removal, and may further accentuate insulin resistance [26].

Additionally, our subjects with hyper-TC, hyper-LDL$\mathrm{C}$ and hyper-non-HDL-C alone or combined with obesity in T2DM group have shown poorly controlled HbA1c as compared to those with normal level of these parameters. Several reports have shown significant influence of lipid concentration on hemoglobin glycation and increased CVD risk possibly due to increased insulin resistance [27-29]. Nonetheless, these studies had stratified subjects based on their glycation control and observed their overall mean of lipid parameters, whereas in our study we had stratified subjects based on their dyslipidemia and obesity followed by observation of glycation pattern. Hyperglycemia promotes increase in LDL glycation and affinity towards LDL-receptors on macrophages; stimulate foam cell formation, endothelial cell toxicity and smooth muscle proliferation responsible for coronary artery and macrovascular complications [1].

We observed a significant association of non-HDL-C with $\mathrm{HbA1c}$ in our study which is in accordance with a recent study in Nepalese' T2DM subjects [27]. Recent studies have also shown the utility of non-HDL-C as a significant biomarker for cardiovascular risk assessment and as a secondary target to monitor the effect of lipid lowering agents $[3,20]$. It can be inferred that subjects with hyper-non-HDL-C are at an increased risk of CVD.

Our study could not demonstrate significant association of hyper-TG levels in T2DM subjects as compared to non-diabetic control subjects, contrary to the studies by Ikhas et al., and Schulze et al., which could be due to poor glycemic control that mask the effects of TG in higher glycation group [29, 30].

The Lipid Research clinics Coronary Primary Prevention Trial established that each $1 \%$ fall in TC levels results into $2 \%$ reduction in CAD risk [31]. A study carried out in Helsinki determined that with $11 \%$ fall in LDL-C levels, there is $34 \%$ reduced risk of CAD [31]. 
The present study observed an incidence of hyper-TC in $19.77 \%$ of T2DM and $20.56 \%$ of non-diabetic controls.

Moreover an increased dyslipidemia is likely to increase $\mathrm{HbA} 1 \mathrm{c}$ and vice versa as the correlation between these parameters are directly proportional and goes hand-in-hand [27, 32]. Reduction in HbA1c in T2DM is associated with improved insulin sensitivity and better lipid parameters.

There are several mechanisms to elicit the effects of increased physical activity to improve dyslipidemia as it increases glucose removal and decreases muscle and hepatic IR through a number of mechanisms that would not necessarily be associated with changes in body weight [33]. This is in accordance with our results where we could not find correlation of HbA1c with BMI (which is an indicator of overall weight gain). However, increased physical activity and lifestyle modification seems to be associated with decreased HbA1c and better glycemic and lipid control. Thus, targeting to lower the dyslipidemia and obesity is likely to reduce $\mathrm{HbA1c}$ not only in diabetic subjects but it will have an equal effect in non-diabetic subjects.

\section{Conclusion}

Dyslipidemia and obesity are significantly associated with poorly controlled hemoglobin glycation in T2DM and non-diabetic subjects. Additionally, higher prevalence of non-HDL-C in the study subjects suggesting its possible role as a biomarker for CVD.

\begin{abstract}
Abbreviations
T2DM: Type 2 diabetes mellitus; CVD: Cardiovascular disorders; HbA1c: Hemoglobin glycation; TC: Total cholesterol; TG: Triglyceride; HDL-C: High-density-lipoprotein cholesterol; LDL-C: Low-density-lipoprotein cholesterol; non-HDL-C: Non-High-density-lipoprotein cholesterol; CAD: Coronary artery disease; VLDL: Very-Low-density-lipoproteins; IDL: Intermediate- density-lipoproteins; NCEP-ATP III: National Cholesterol Education Program, Adult Treatment Panel III; WHO: World Health Organization; BMI: Body mass index; NEFA: Non-esterified fatty acids; IDF: International Diabetes Federation; ISBEC: Intersystem Biomedica Ethics Committee; WC: Waist circumference; FPG: Fasting plasma glucose; PPPG: Post prandial plasma glucose; FI: Fasting insulin; IRMA: Immune Radiometric Assay; HOMA-IR: Homeostasis Model of Assessment-Insulin Resistance Index; CHD: Coronary heart disease; DCCT: The Diabetes Complications and Control Trial.
\end{abstract}

\section{Competing interests}

The authors declare no conflict of interest that could be perceived as prejudicing the impartiality of this research. None of the authors is involved in the financial support that might potentially bias his or her work.

\section{Authors' contributions}

JS has designed, standardized the protocol, and contributed in writing the MS. AS has carried out the practical work, statistical analysis and interpretation of the results and written the MS. FS has contributed in evaluating the MS. ST has contributed in evaluating the MS. NN has carried out partial practical work. PT and NS have contributed patients' referral with RV. RV was involved in designing clinical record form, evaluating MS. All authors reviewed and approved of the final manuscript.

\section{Acknowledgements}

This part of the study was funded by GICT (Gujarat Institute of Chemical Technology), which we gratefully acknowledge. Our sincere thanks to Mrs. Jyothi Lekshmi and Dr. Mamta Lele for their partial technical help. Special thanks to Mr. Harsh Sheth for his valuable suggestions in statistical analysis and proof reading of the manuscript. Sincere thanks to all the clinicians for their co-operation and kind referrals. We wish to express a deep sense of gratitude for the participating subjects and their families who have made this study possible.

\section{Author details}

'Department of Biochemistry and Molecular Genetics, FRIGE's Institute of Human Genetics, FRIGE House, Jodhpur Gam Road, Satellite, Ahmedabad 380015, India. ${ }^{2}$ Unit of Endocrine and Metabolic Disorders, Kasturba Health Society, Medical Research Centre Mumbai 400056, India. ${ }^{3}$ Department of Diabetes and Endocrinology, Sterling Hospital Ahmedabad 380052, India. ${ }^{4}$ Gujarat Diabetic Association Ahmedabad 380007, India.

Received: 1 January 2015 Accepted: 18 May 2015

Published online: 23 June 2015

\section{References}

1. Singh AK, Singh SK, Singh N, Agrawal N, Gopal K. Obesity and dyslipidemia. Int J Biol Med Res. 2011;2(3):824-8.

2. Executive summary of the Third Report of The National Cholesterol Education Program (NCEP) Expert Panel on detection, evaluation, and treatment of high blood cholesterol in adults (Adult Treatment Panel III). JAMA 2001;285:2486-97. doi:10.1001/jama.285.19.2486.

3. Peters A. Clinical Relevance of Non-HDL Cholesterol in Patients with Diabetes. Clinical Diabetes. 2008;26(1):1-7.

4. Online Mendelian Inheritance in Man (OMIM), http://www.omim.org/entry/ 601665, accessed on 09/07/2014.

5. Global Health Observatory. Obesity: situation and trends. World Health Organization. 2013. Available from: http://www.who.int/gho/ncd/ risk_factors/obesity_text/en/index.html, accessed on 09/07/2014.

6. Lewis CE, MCTigue KM, Burke LE, Poirier P, Eckel RH, Howard BV, et al. Mortality, health outcomes, and body mass index in the overweight range: A science advisory from the American Heart Association. Circulation. 2009;119:3263-71. Doi: 10.1161/CIRCULATIONAHA.109.192574.

7. Sabale BB, Barhate AA. Study of prevalence of overweight and obesity in shopkeepers in wetern Maharashtra. Indian Journal of Basic and Applied Medical Research. 2014;3(2):419-22.

8. Raji A, Seely EW, Arky RA, Simonson DC. Body Fat Distribution and Insulin Resistance in Healthy Asian Indians and Caucasians. J Clin Endocrinol Metab. 2001;86(11):5366-71.

9. Kahn S, Hull R, Utzschneider M. Mechanisms linking obesity to insulin resistance and type 2 diabetes. Nature. 2006;444(7121):840-6.

10. Ginsberg H, Plutzky J, Sobel BE. A review of metabolic and cardiovascular effects of oral antidiabetic agents: beyond glucose-level lowering. J Cardiovasc Risk. 1999;6:337-46.

11. Forouhi N: Ethnicity and metabolic syndrome. In: The metabolic syndrome. Edited by: Byrne CD and Wild SH. England: John Wiley \& Sons; 2006: 46-47. ISBN 0555050005-5.

12. Indian statistics. http://infograficsmania.com/india-obesity-statistics/ assessed on $11 / 12 / 2014$

13. Shaw JE, Sicree RA, Zimmet PZ: Global estimates of the prevalence of diabetes for 2010 and 2030. Diabetes res clin prac 2010, 87: 4-14.

14. World Health Organization: Definition, diagnosis and classification of diabetes mellitus and its complications: report of a WHO consultation. Part 1, Diagnosis and classification of diabetes mellitus. 1999. http://www.who.int/iris/ handle/10665/66040\#sthash.7F60S1LB.dpuf.

15. Balkau B, Charles MA. Comment on the provisional report from the WHO consultation. Diabetic Medicine. 1999;16:442-3.

16. American Diabetes Association. Diagnosis and classification of diabetes mellitus. Diabetes Care. 2009:32:62-7.

17. IDF: Diabetes atlas 2013, International Diabetes Federation. $6^{\text {th }}$ ed. www.idf.org/diabetesatlas assessed on 11/12/2014.

18. Fonseca VA: Defining and Characterizing the progression of Type 2 Diabetes. Diabetes Care 2009, 32(supplement 2): S151-S156. doi: 10.2337/dc09-S301. 
19. Jain M, Jadeja JM, Mehta N. Correlation Between HbA1C Values And Lipid Profile In Type 2 Diabetes Mellitus. International Journal of Basic and Applied Physiology. 2013;2(1):47-50

20. Virani SS: Non-HDL Cholesterol as a Metric of Good Quality of Care Opportunities and Challenges. Texas Heart Institute Journal 2011;38(2):160-162.

21. Matthews DR, Hosker JP, Rudenski AS, Naylor BA, Treacher DF, Turner RC. Homeostasis model assessment: Insulin resistance and $\beta$-cell function from fasting plasma glucose and insulin concentrations in man. Diabetologia. 1985;28:412-9.

22. Online sample size calculator by Raosoft, Inc. http://www.raosoft.com/ samplesize.html, accessed on 09/07/2014.

23. Misra A, Khurana L. Obesity and the metabolic syndrome in developing countries. J Clin Endocrinol Metab. 2008;93(11):9-30.

24. Soodini GR, Hamdy O: Adiponectin and Leptin in Relation to Insulin Sensitivity. Metab Syndr Relat Disord 2004;2(2):114-123.

25. McTernan CL, McTernan PG, Harte AL, Levick PL, Barnett AH, Kumar S. Resistin, central obesity, and type 2 diabetes. Lancet. 2002;359:46-7.

26. Hayashi T, Boyko EJ, Leonetti DL, Mcneely M, Morris L, Kahn S, et al. Visceral adiposity and the risk of impaired glucose tolerance: A prospective study among Japanese Americans. Diabetes Care. 2003;26:650-5.

27. Mahato RV, Gyawali P, Raut P, Regmi P, Singh K, Pandeya DR, et al. Association between glycaemic control and serum lipid profile in type 2 diabetic patients: Glycated haemoglobin as a dual biomarker. Biomedical Research. 2011;22(3):375-80.

28. Charitha B, Senghor AR, Shivashekar M, William E. Glycated Hemoglobin as a Dual Marker: In Control of Glycemic Status and Diabetic Dyslipidemia. International Journal of Pharmaceutical and Clinical Research. 2013;5(3):111-3.

29. Hammed IK, Abed BA, Rashid NF. Glycated haemoglobin as a dual biomarker Association between $\mathrm{HbA} 1 \mathrm{c}$ and dyslipidemia in type 2 diabetic patients. J Fac Med Baghdad. 2012;54(1):88-92.

30. Schulze MB, Shai I, Manson JE, Li T, Rifai N, Jiang R, et al. Joint role of non-HDL cholesterol and glycated haemoglobin in predicting future coronary heart disease events among women with type 2 diabetes. Diabetologia. 2004;47:2129-36. Doi: 10.1007/s00125-004-1593-2.

31. Prabhavathi K, Kirthana KU, Jaisri G. Glycosylated Haemoglobin (HbA1c) - A Marker of Circulating Lipids in Type 2 Diabetic Patients. Journal of Clinical and Diagnostic Research. 2014;8(2):20-3.

32. DCCT Research Group. The absence of a glycemic threshold for the development of long-term complications: The perspective of the diabetes control and complications trial. Diabetes. 1996;45(10):1289-98.

33. Sanghani NB, Parchwani DN, Palandurkar KM, Shah AM, Dhanani JV. Impact of lifestyle modifi cation on glycemic control in patients with type 2 diabetes mellitus. Indian J Endocr Metab. 2013;17:1030-9.

\section{Submit your next manuscript to BioMed Central and take full advantage of:}

- Convenient online submission

- Thorough peer review

- No space constraints or color figure charges

- Immediate publication on acceptance

- Inclusion in PubMed, CAS, Scopus and Google Scholar

- Research which is freely available for redistribution

Submit your manuscript at www.biomedcentral.com/submit 